\title{
MULTI-MODAL ANALYSIS OF VIBTATION AND METEOROLOGICAL DATA FOR STRUCTURES ON THE WORLD HERITAGE SITE “BATTLESHIP ISLAND”
}

\section{NARITO KURATA ${ }^{1 *}$, KAZUKI TAKAI ${ }^{2}$, AKIHIRO TOMIOKA ${ }^{2}$, TAKUYA DAIGO ${ }^{2}$, SHUNSUKE SARUWATARI ${ }^{3}$ AND TAKUJI HAMAMOTO ${ }^{4}$}

${ }^{1}$ Graduate School of Technology and Science

Tsukuba University of Technology (NTUT)

3-4-15 Amakubo, Tsukuba city, Ibaraki 305-8520, Japan

e-mail: kurata@home.email.ne.jp, www.tsukuba-tech.ac.jp/english

${ }^{2}$ Akishima Plant

Japan Aviation Electronics Industry, Ltd. (JAE)

3-1-1 Musashino, Akishima city, Tokyo, 196-8555, Japan

email: \{ takaikz, tomiokaa, daigot \}@ jae.co.jp, www.jae.com/en

${ }^{3}$ Graduate School of Information Science and Technology

Osaka University

1-5 Yamadaoka, Suita, Osaka, 565-0871, Japan

email: saru@ist.osaka-u.ac.jp, www.osaka-u.ac.jp/en

${ }^{4}$ Tokyo City University (TCU)

1-28-1 Tamazutsumi, Setagaya-ku, Tokyo, 158-8557, Japan

email: hamamoto325@gmail.com, www.tcu.ac.jp/english

Keywords: Structural Health Monitoring, Vibration Measurement, Meteorological Observation, Accelerometer

\begin{abstract}
This paper reports the results of vibration and meteorological observations of a buildng built on Hashima, Nagasaki, southern part of Japan, which was registered as a World Heritage Site in $2015^{[1]}$, and analyzes its dynamic characteristics. Hashima is called "Battleship Island" because its appearance resembles a battleship due to the many buildings standing upon it. The structure contributing most to the battleship appearance is No. 3 Building. An accelerometer and a weather sensor have been installed in No. 3 Building for long-term measurements. Multi-modal analysis of vibration and meteorological data was performed for 5 months, and the dynamic characteristics of No. 3 Building were examined.
\end{abstract}

\section{INTRODUCTION}

Hashima Island in Nagasaki City in the south of Japan was registered as a World Cultural Heritage in $2015^{[1]}$. The island was an offshore city that prospered as an undersea coal mine from the 1800s, and had a population density higher than that of Tokyo. The shape of the island resembles that of a battleship, so it is also referred to as "Battleship Island" (or Gunkanjima). 
As a result of the effect of the energy policy from the 1970s onwards the mine closed on 15th January 1974. Thereafter Battleship Island became unoccupied, but a group of building structures that are degrading with time under the severe natural environment remain. The authors have installed various types of sensors on the group of structures on Battleship Island, and are performing monitoring ${ }^{[2]}$. Building No. 3 contributes most to the resemblance of the silhouette of this island to a battleship. It is the most important among the structures of Battleship Island and must be preserved. A new vibration monitoring system was installed on Building No. 3 in May 2019. Building No. 3 is a 4-story reinforced concrete structure; a total of ten accelerometers were installed on each floor on both sides of the rectangular plan, and vibration measurements for the structural health monitoring ${ }^{[3]}$ have been carried out over several months. Every two hours microtremor measurements are performed for 10 minutes, and in addition when vibrations exceeding a certain level occur such as during typhoons and earthquakes, vibration measurements are taken. On the other hand, meteorological sensors were installed on the rooftop of Building No. 3 in October 2017, measuring items such as air temperature, humidity, atmospheric pressure, wind direction, wind velocity, sunlight intensity, and rainfall. This paper presents the results of analysis of the dynamic properties of Building No. 3, obtained from a multi-modal analysis of the vibration data and the meteorological data.

\section{NO.3 BUILDING, THE SYMBOL OF BATTLESHIP ISLAND}

\section{Building on Battleship Island, shown in Fig. 1, is a 4-story reinforced concrete housing} complex constructed in symbolic building that new on the island, with wireless antenna for maritime opposite shore, a solar pane surrounding area are installed. These serve as corr.
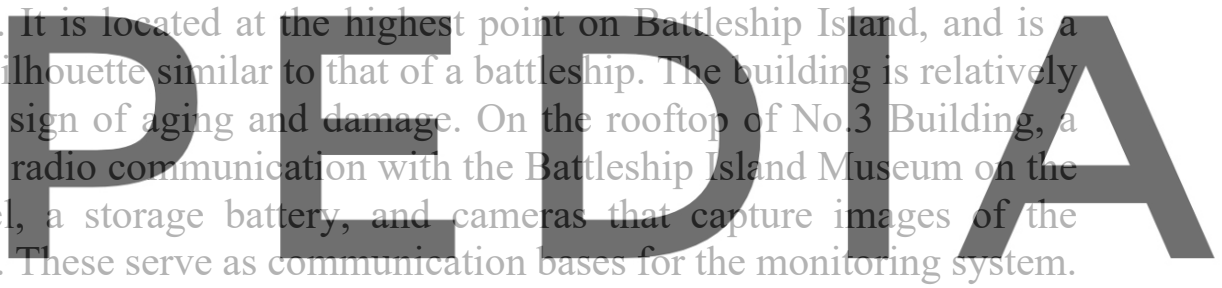

Register for free at https//www.scipedia.com to download the version without the watermark

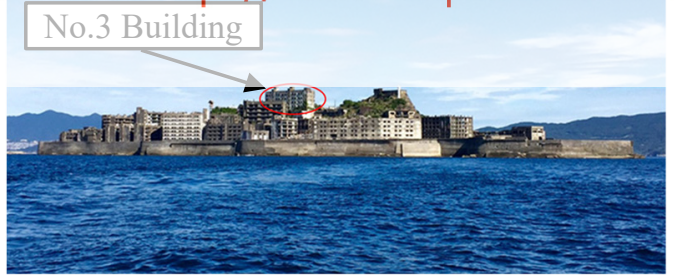

(a) Panoramic View

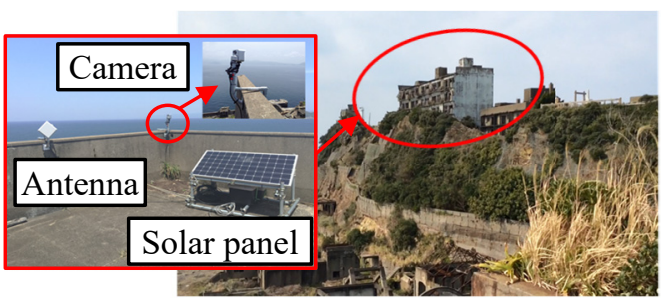

(b) Camera, Energy and Network System

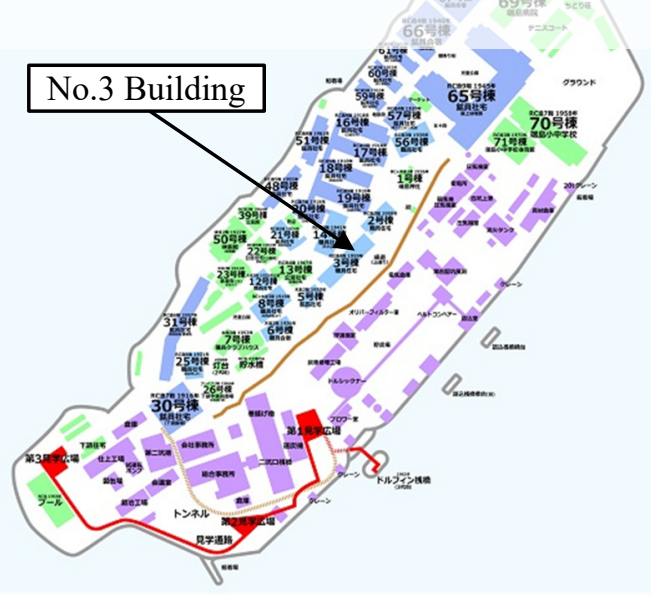

(c) Plan View

Figure 1: No.3 Building 


\section{VIBRATION MEASUREMENT SYSTEM}

Fig. 2 shows the locations of the accelerometers in No. 3 Building ${ }^{[4]}$. No. 3 Building has a flat, rectangular shape, with a total of 10 acceleration sensors installed on both sides of each floor. Fig. 3 and Table 1 show the system configuration and the specifications of the acceleration sensors ${ }^{[5]}$. The accelerometers used are JA-70SA manufactured by Japan Aviation Electronics Industry. This accelerometer can measure a wide range of vibrations from microtremors, to strong vibrations during a typhoon or large earthquake. For vibration measurement, a data acquisition device (referred to as a DAQ) having a 16-channel A/D conversion module is used, and synchronization is performed to within $5 \mu \mathrm{sec}$ by a multiplexer at the preceding stage. Time synchronization is performed by GPS, and the sampling frequency is set to $100 \mathrm{~Hz}$. A continuous measurement function that saves 10 minutes of measurement data every 2 hours and a trigger function that stores measurement data when more than a certain level of vibration occurs due to a typhoon or an earthquake are installed. The data stored in the data recorder is transmitted to a data server in the Battleship Island Museum on the opposite shore by a maritime radio communications antenna (see Fig. 1) installed on the rooftop. This data server is accessible via the Internet. Solar panels and storage batteries are installed on the rooftop of the structure to serve as a power source for the vibration measurement system. PCs, the DAQ and accelerometers consume higher power, but they use system power efficiently to provide constant remote monitoring and continuous measurement.
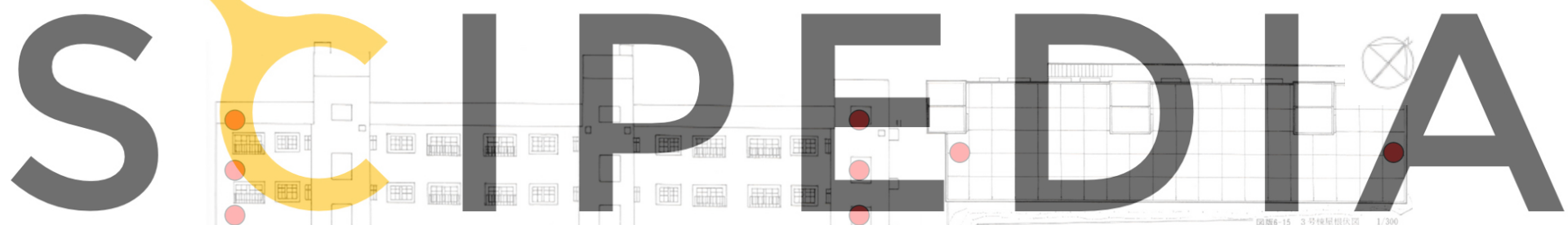

Register for free at https//www.scipedia.com to download the version without the watermark
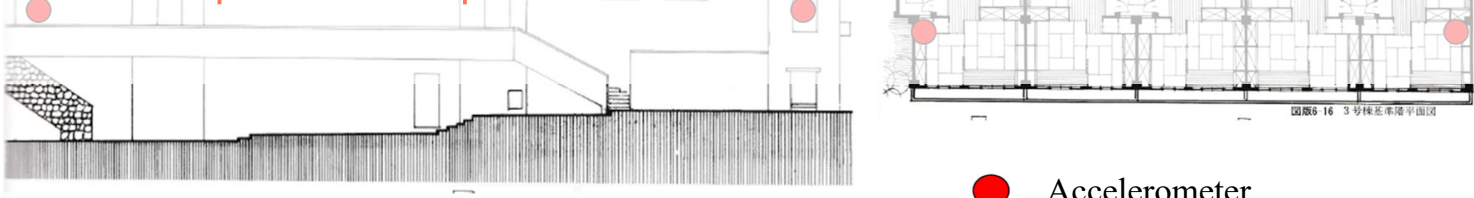

Accelerometer

Figure 2: Sensor Location

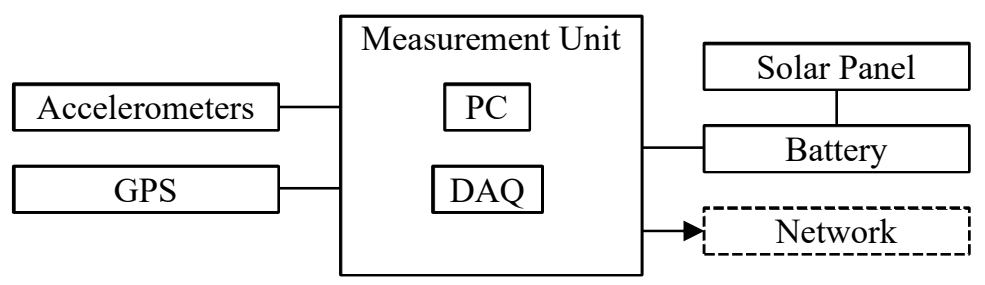

Figure 3: Vibration Measurement System 
Table 1: Specifications of Accelerometer

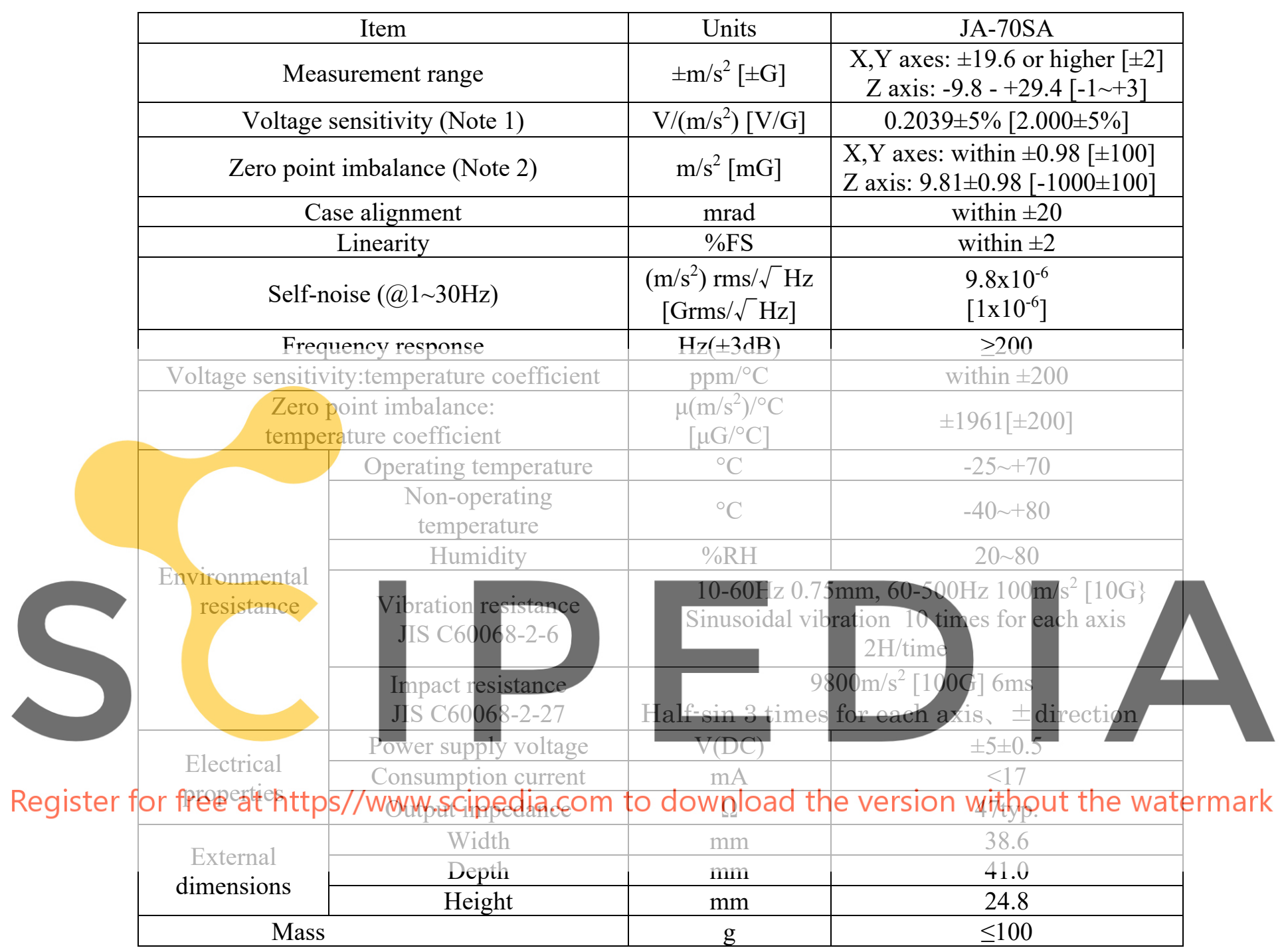

\section{AUTONOMOUS METEOROLOGICAL OBSERVATION SYSTEM}

An autonomous meteorological observation system (Meisei Electric, POTEKA) is installed on the rooftop of No. 3 Building (see Fig. 4) ${ }^{[6]}$. As shown in Fig. 4(a), the system includes solar panels, storage batteries, a radio communication unit, a weather sensor station, rain gauges, and a base for fixing these devices. The weather sensor station comprises 7 types of sensors (temperature, pressure, humidity, solar radiation, wind direction, wind speed, and precipitation) as shown in Fig. 4(b). Because observation data is updated every minute, it is possible to capture changes in weather conditions in real-time. The weather data is transmitted to the server in realtime via a mobile phone network. Table 2 shows the specifications of the autonomous meteorological observation system, and Table 3 shows the specifications of the weather sensors. 


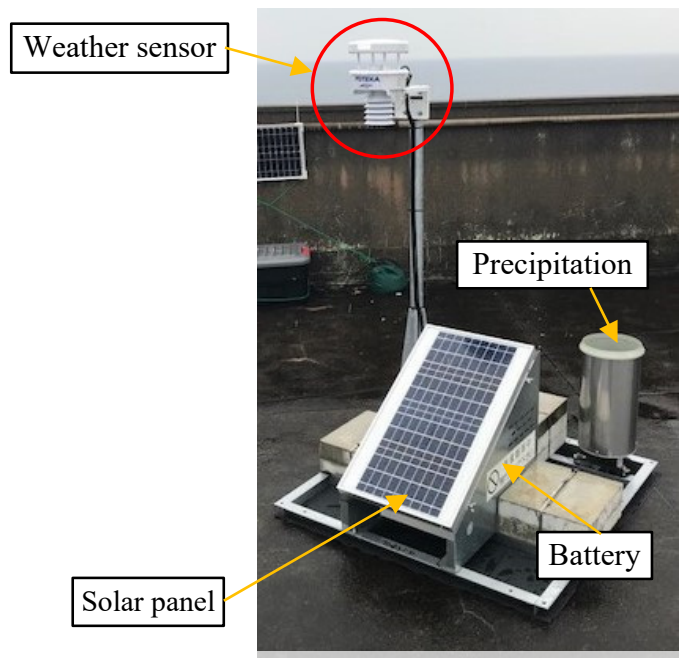

(a) System View

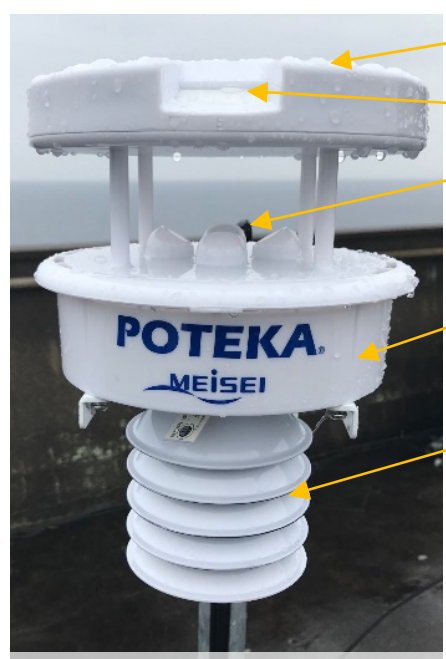

(b) Weather Sensor \begin{tabular}{|c|}
\hline Solar radiation \\
\hline Rainfall \\
\hline
\end{tabular}

Wind

direction/speed

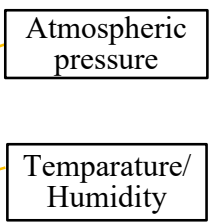

Figure 4: Meteorological Observation System

Table 2: Specifications of Meteorological Observation System

Observation element of weather

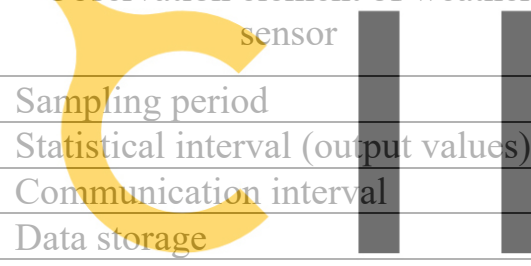

Solar battery capacity
Air temperature, atmospheric pressure, humidity, solar

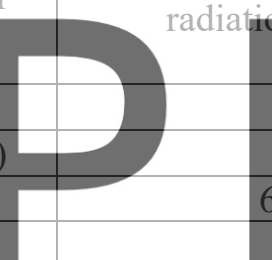

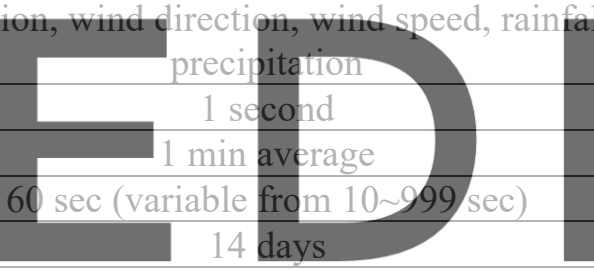

$30 \mathrm{~W}$

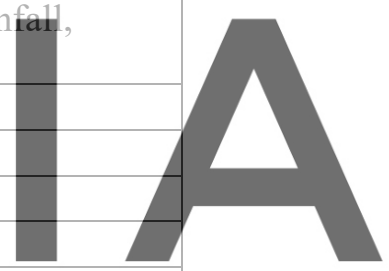

Register fortafrege cetl hapacity/www.scipedia.com to download the version without the watermark Built-in cell

Power interruption backup time

Operating temperature range

Wind speed resistance

Communications circuit

Nickel-hydrogen cell $700 \mathrm{mAh}$

More than 6 hrs. $-10^{\circ} \mathrm{C} \sim+60^{\circ} \mathrm{C}$

Average wind speed $60 \mathrm{~m} / \mathrm{s}$ $3 \mathrm{G}$ circuit

Table 3: Specifications of Weather Sensor

\begin{tabular}{|l|l|c|c|}
\hline \multicolumn{1}{|c|}{ Element } & Measurement method & Observation range & Precision \\
\hline Air temperature & Platinum resistor & $-50.0 \sim+50.0^{\circ} \mathrm{C}$ & $\pm 0.3^{\circ} \mathrm{C}$ \\
\hline Humidity & Capacitive type & $0.0 \sim 100.0 \% \mathrm{RH}$ & $\pm 5 \%$ \\
\hline Atmospheric pressure & Capacitive type & $870.0 \sim 1050.0 \mathrm{hPa}$ & $\pm 0.7 \mathrm{hPa}$ \\
\hline Wind direction & Ultrasonic & $0 \sim 360^{\circ}$ & $\pm 10^{\circ}$ \\
\hline Wind speed & Ultrasonic & $0.0 \sim 30.0 \mathrm{~m} / \mathrm{s}$ & $\begin{array}{c} \pm 0.3 \mathrm{~m} / \mathrm{s}(0 \sim 10 \mathrm{~m} / \mathrm{s}) \\
\pm 5 \%(10 \sim 30 \mathrm{~m} / \mathrm{s})\end{array}$ \\
\hline Solar radiation & Photodiode & $0 \sim 1400 \mathrm{~W} / \mathrm{m}^{2}$ & $\pm 10 \%$ \\
\hline Rainfall & Capacitive type & $0 / 1$ & - \\
\hline Precipitation & Tipping bucket type & Below $200 \mathrm{~mm} / \mathrm{h}$ & $\begin{array}{c} \pm 0.5 \mathrm{~mm}(\text { below } 20 \mathrm{~mm}) \\
\pm 3 \% \text { (above } 20 \mathrm{~mm})\end{array}$ \\
\hline
\end{tabular}




\section{ANALYSIS OF VIBRATION AND METEOROLOGICAL DATA}

Figs. 5 and 6 show amplitude ratios of Fourier acceleration spectra on the rooftop and the first floor calculated from acceleration data measured for 10 minutes from 12:00 every day, from June 1 to October 18, 2019. As can be seen from the figures, some parts of the data from August 12 to 19 and August 27 to 28 during the measurement period are missing. In each figure, the measurement dates, frequencies, and ratios of Fourier spectra are displayed in 3D and 2D. In addition, the dates of occurrence of three typhoons that caused strong vibrations in No. 3 Building during the measurement period are shown. Fig. 5 shows the analysis results of the long-side components of the sensors installed on the south and north sides of No. 3 Building. From these figures, it can be seen that the first characteristic frequency clearly appears around $6 \mathrm{~Hz}$ during strong winds or a typhoon. In addition, characteristic frequencies of higher-order modes can be observed near $17 \mathrm{~Hz}$. Further, if vibration of the building increases due to strong winds or a typhoon, vibration in the high frequency region of $10 \mathrm{~Hz}$ or more increases on the south side.
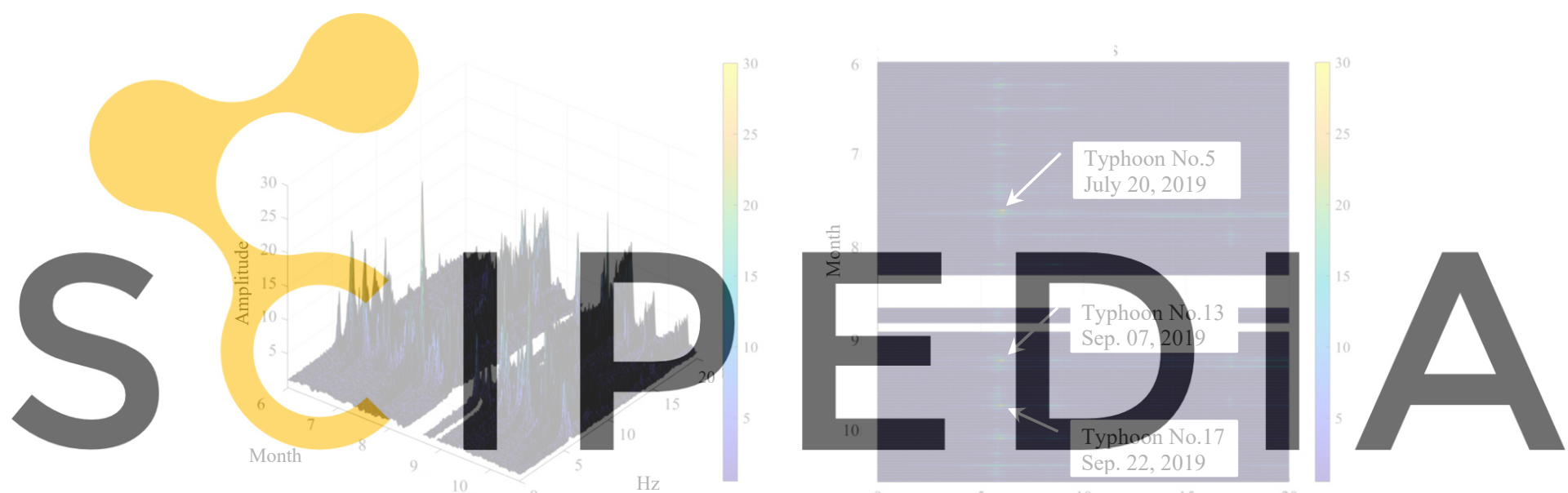

Register for free at https//www.scipedia.com to download the version without the watermark (a) South side (3D) (b) South side (2D)

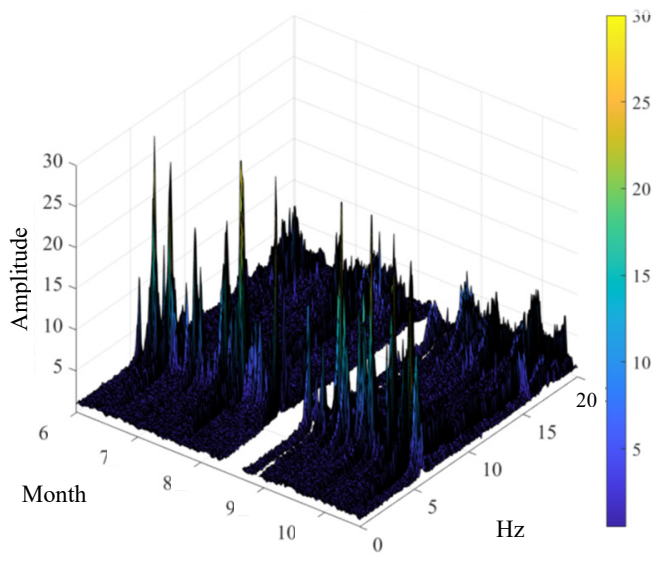

(c) North side (3D)

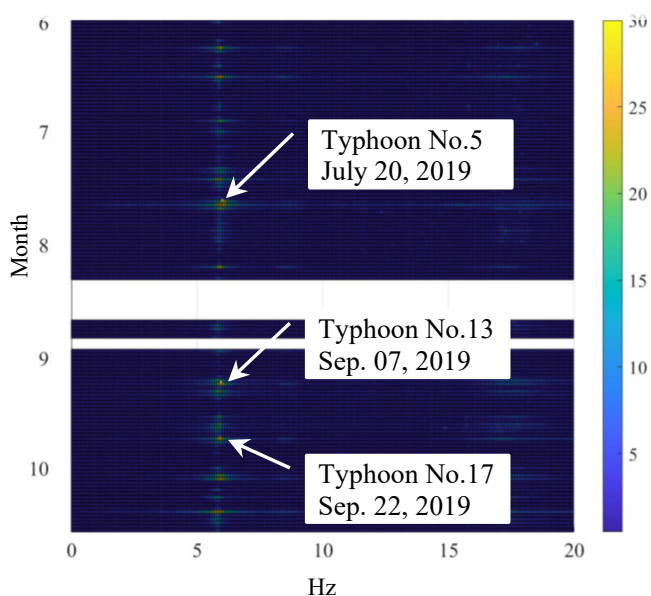

(d) North side (2D)

Figure 5: Fourier amplitude spectrum ratios of the acceleration data (Long-side component) 
Fig. 6 shows the analysis results of the short-side components of the sensors installed on the south and north sides of No. 3 Building. From these figures, it can be seen that characteristic frequencies appear at around $9 \mathrm{~Hz}$ and $14 \mathrm{~Hz}$ in addition to $6 \mathrm{~Hz}$ during strong winds or a typhoon. Further, when vibration of the building increases due to strong winds or a typhoon, the vibration on the south side is larger than that on the north side, and on the south side, vibration in the high frequency region of $10 \mathrm{~Hz}$ or more increases.

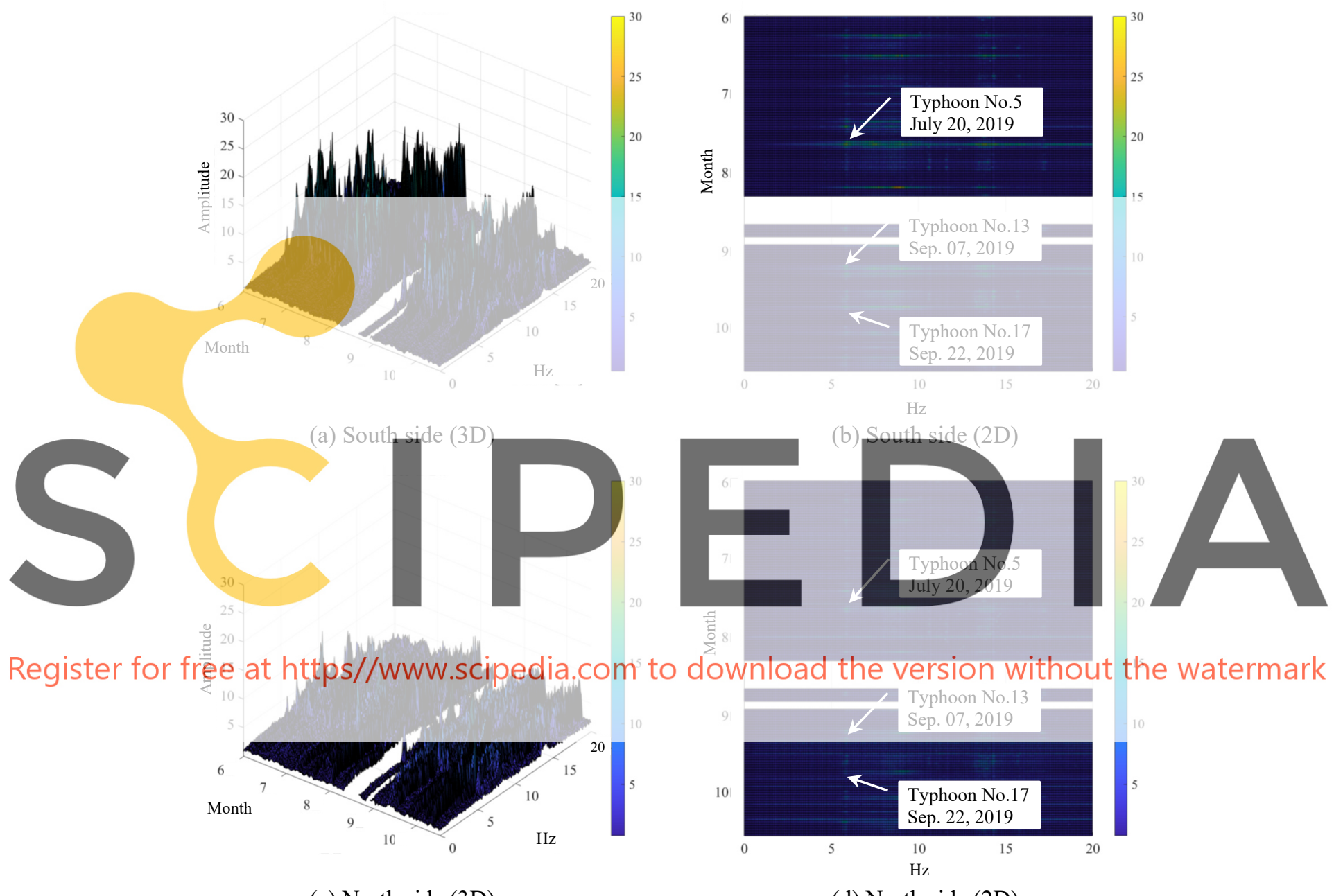

(c) North side (3D)

(d) North side (2D)

Figure 6: Fourier amplitude spectrum ratios of the acceleration data (Short-side component)

Fig. 7 shows the average air temperature and the maximum instantaneous wind speed every 10 minutes, measured from June 1, 2019 to October 18, 2019. This figure also shows the dates of three typhoons that caused large vibrations in No. 3 Building during the measurement period. When the wind speed increases due to a typhoon, the vibration of the building increases, but in No. 3 Building, vibrations other than the characteristic frequencies are excited. As an example, Fig. 8 shows Fourier acceleration spectrum ratio of the roof and first floor in the short-side direction on the south side of the building calculated from acceleration data measured during 
Typhoon No. 5. The figure shows the analysis results of data measured for 10 minutes every 2 hours, for 48 hours from 12:00 on July 19 until 12:00 on July 21, or from when Typhoon No. 5 approached until it passed. In the figure, the time zone where the wind speed is high is clearly indicated by the red frame. As the wind speed increases due to the typhoon, the vibration of the building increases, and it can be seen that on the south side of the building, vibrations in the high frequency region of $10 \mathrm{~Hz}$ or more are excited.

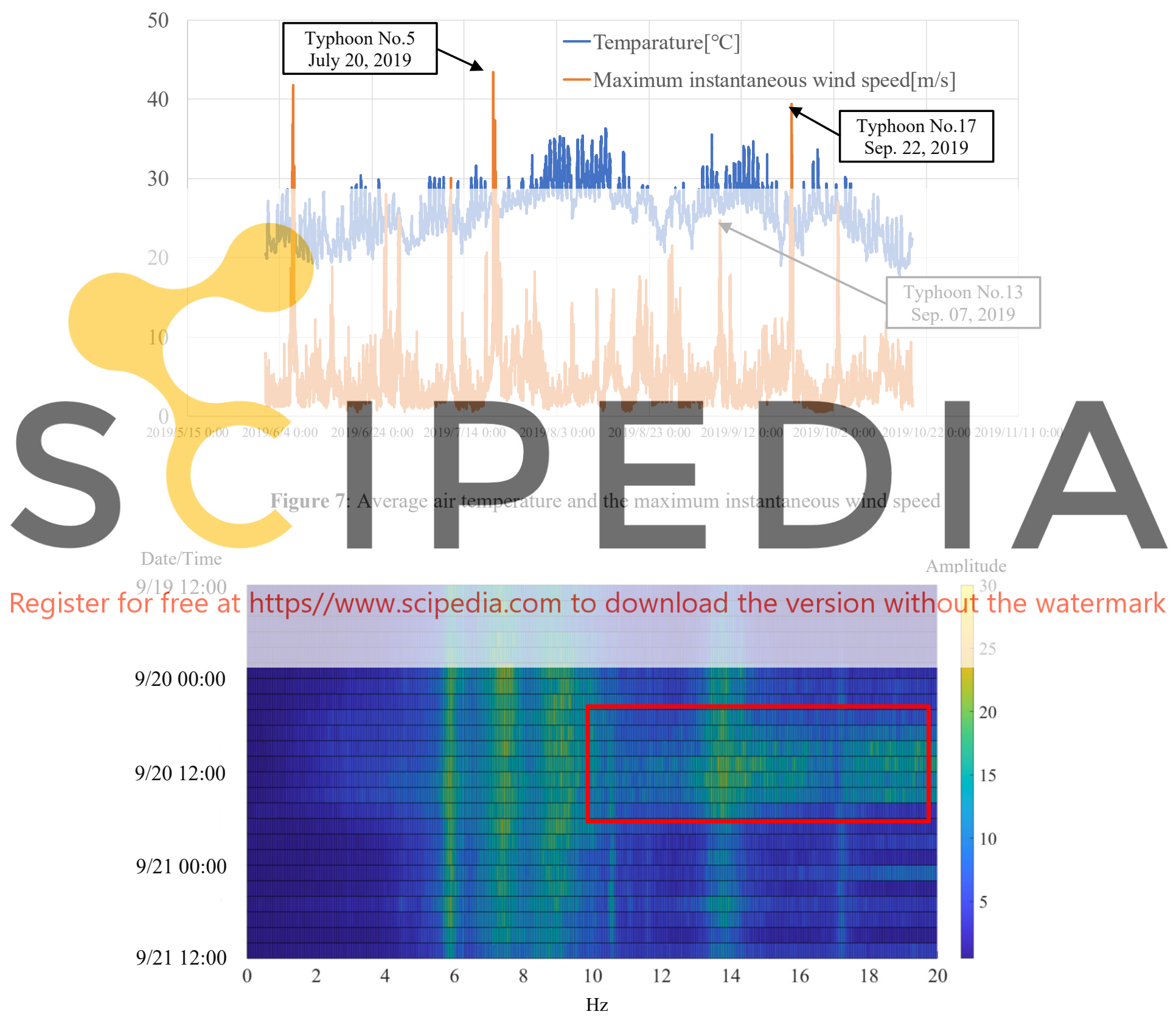

Figure 8: Fourier amplitude spectrum ratios of the acceleration data (Short-side component) 


\section{CONCLUSIONS}

In this paper, vibration measurements and meteorological observations were made on the building of Battleship Island, which is registered as a World Cultural Heritage site, and their dynamic characteristics were analyzed. In the target, No. 3 Building, no change in low-order mode dynamic characteristics due to temperature changes from spring to autumn was observed. It was found that when vibration of the building increased due to strong winds or a typhoon, vibration on the south side was larger than that on the north side, and vibration in the high frequency region was also larger. This suggested that, by observing the fluctuations of low frequency region on the south side after large vibrations occur due to strong winds, a typhoon or an earthquake, it is possible to detect loss of structural stability of the building. In the future, it is planned to continue vibration measurements and meteorological observations for No. 3 Building, and compare the measurement results on a yearly basis including winter.

Acknowledgements. This work was supported by JSPS KAKENHI JP17KT0042 and JP26289194. Nagasaki City cooperated with the installation and measurement on the island.

The photos were taken with the special permission of Nagasaki City.

\section{REFERENCES}

[1] World Heritage Committee. Decisions adopted by the World Heritage Committee at its 39th

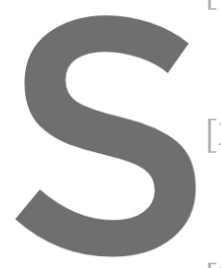
session (Bonn, 2 (2015).

Hamamoto, T., Kurata, N., St Test of Change Detect in GUNKANJIMA. AIJ J.
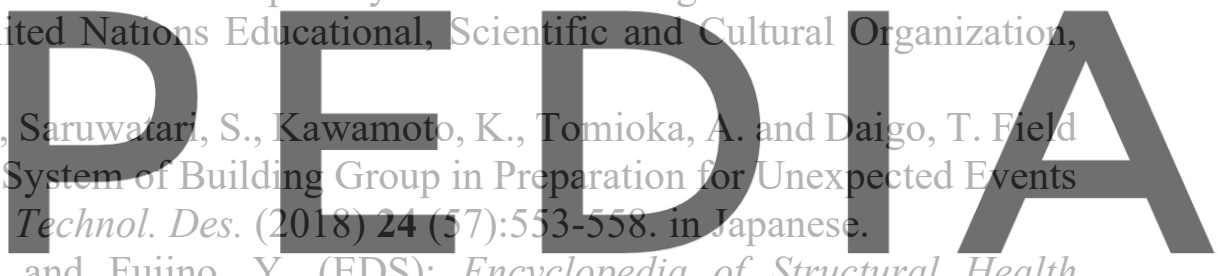

Boller, C., Chang, F-K. and Fujino. Y. (EDS): Encyclopedia of Structural Health

Register for freenitaring

[4] Akui, Y. and Shiga, H. Gunkanjima Survey Data Collection (Supplementary Edition), Tokyo Denki University Press, 2005. in Japanese.

[5] Tomioka, A., Hamamoto, T., Kurata, N. and Saruwatri, S. Gunkanjima Monitoring Project Part 10: Configuration of MEMS Accelerometer Network. Summaries of technical papers of annual meeting, Architectural Institute of Japan (2018), pp. 151-152. in Japanese.

[6] Kurata, N., Sasaki, K., Saruwatari, S., Hamamoto, T. and Tomioka, A. Gunkanjima Monitoring Project Part 11: Autonomous Weather Sensor System installed at the No.3 Building. Summaries of technical papers of annual meeting, Architectural Institute of Japan (2018), pp. 83-84. in Japanese. 